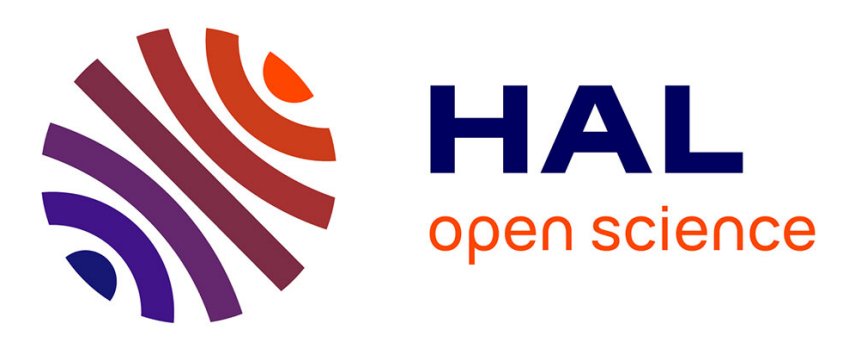

\title{
Use of marine compounds to treat ischemic diseases
}

\author{
Catherine Boisson-Vidal
}

\section{To cite this version:}

Catherine Boisson-Vidal. Use of marine compounds to treat ischemic diseases. Stéphane La Barre; Stephen S Bates. Blue Biotechnology: Production and Use of Marine Molecules, 1, Wiley, pp.267-296, 2018, 978-3527341382. 10.1002/9783527801718.ch9 . hal-02333669

\section{HAL Id: hal-02333669 \\ https://hal.science/hal-02333669}

Submitted on 8 Nov 2019

HAL is a multi-disciplinary open access archive for the deposit and dissemination of scientific research documents, whether they are published or not. The documents may come from teaching and research institutions in France or abroad, or from public or private research centers.
L'archive ouverte pluridisciplinaire HAL, est destinée au dépôt et à la diffusion de documents scientifiques de niveau recherche, publiés ou non, émanant des établissements d'enseignement et de recherche français ou étrangers, des laboratoires publics ou privés. 


\section{Contents}

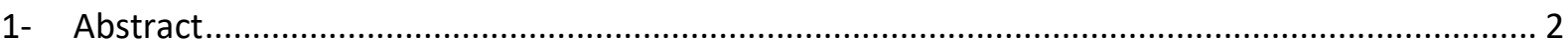

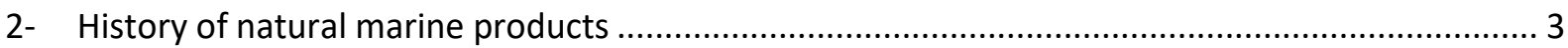

3- Peripheral arterial disease and cardiovascular risks - Treatments and unmet needs.................... 4

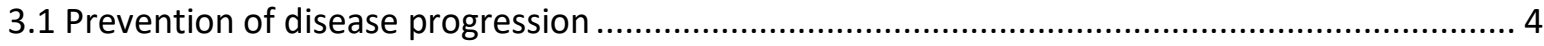

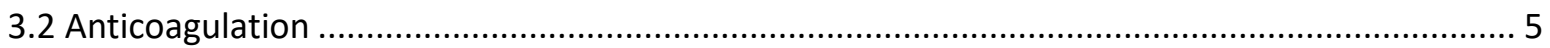

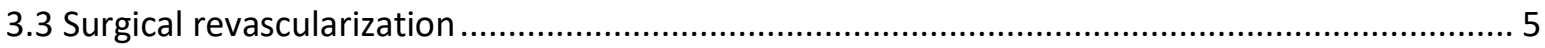

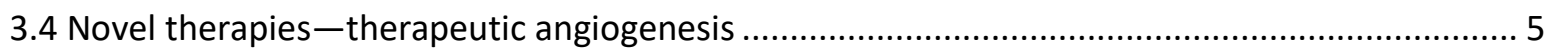

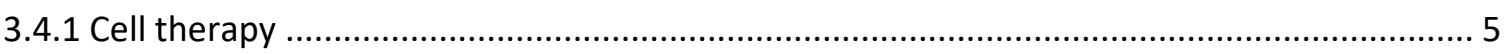

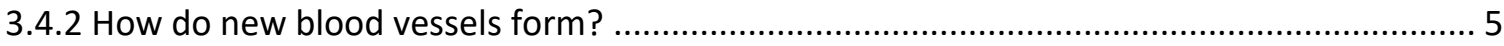

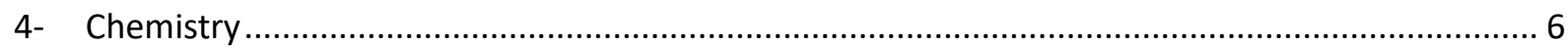

4.1 Extraction and preparation of low-molecular-weight fucoidan fractions.................................. 6

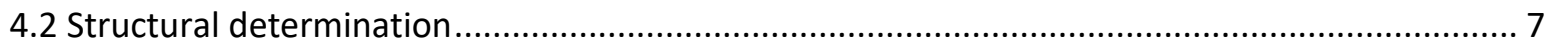

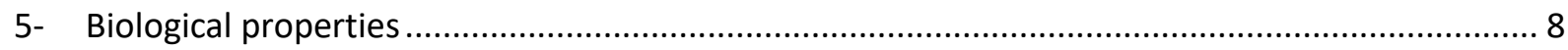

5.1 Marine polysaccharides exhibit anticoagulant activity .......................................................... 8

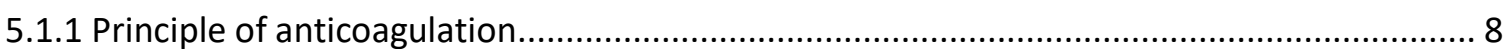

5.1.2 Marine polysaccharides have potent anticoagulant properties ........................................ 8

5.1.3 Fucoidan exhibits venous and arterial antithrombotic properties with no hemorrhagic risk 8

5.2 Marine polysaccharides have angiogenic properties .......................................................... 9

5.2.1 Contrary to other polysaccharides, fucoidan potentiates angiogenesis in vitro and in vivo . 9

5.2.2 Injections of LMW fucoidan induce rapid mobilization of stem cells from bone marrow.... 9

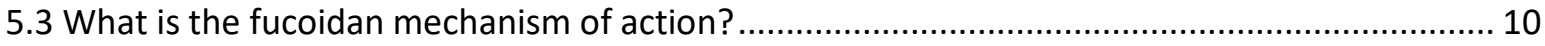

5.3.1 Cellular and molecular mechanisms underlying fucoidan proangiogenic activity............... 10

5.3.2 Fucoidan modulates the biological activity of angiogenic heparin-binding proteins .......... 10

5.3.3 Fucoidan may act as a direct growth-factor signal transducer .......................................... 11

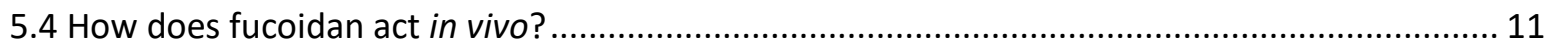

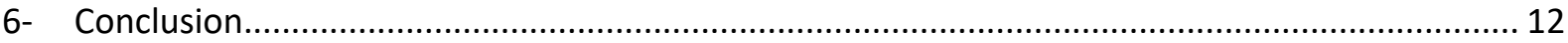

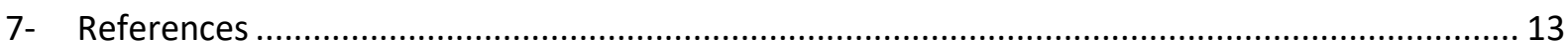




\section{Use of marine compounds to treat}

\section{ischaemic diseases}

Catherine Boisson-Vidal, Unité Inserm 1140 Ithem, Faculté de Pharmacie de Paris, Université Paris Descartes, Sorbonne Paris Cité, 4 avenue de l'observatoire, 75006 Paris, France.

\section{1- Abstract}

The marine reservoir, with its massive biodiversity, likely harbours numerous human drug candidates. Polysaccharides of various marine origins have shown to be good alternatives to mammalian polysaccharides. One well-known example is heparin, a sulphated polysaccharide used in the prevention of thrombosis and pulmonary embolism.

The oldest use of marine polysaccharides concerns those produced by algae. These products form the basis for an economically important and expanding global industry. This chapter provides the historical background to the discovery of the therapeutic potential of these marine compounds, together with their medical and biotechnological applications.

Peripheral arterial disease (PAD) is a progressive disorder due to atherosclerosis (narrowing of the peripheral arteries, especially in the legs). Arterial flow is reduced or discontinuous, causing oxygen deprivation in the underlying tissues and possible tissue necrosis. The primary aim of medical therapy is to increase arterial flow in the affected limb, in order to relieve pain, heal trophic lesions and avoid amputation. Anticoagulant, antithrombotic and antiplatelet agents are used to reduce the risk of thrombus formation. Novel treatments such as therapeutic angiogenesis (promotion of new blood vessel growth) are in the development phase, with promising preclinical data.

Fucoidan is a polysulphated L-fucose endowed with biological activities closely related to its chemical composition (especially the distribution of sulphate groups along its polyfucose backbone), and to its molecular weight. Fucoidans are highly soluble in water, non-toxic and non-immunogenic. Details are provided below on its production and characterization, and on the main chemical characteristics that influence their biological activities. Fucoidan exhibits venous and arterial antithrombotic properties in animal models. In animal experiments, fucoidan promoted the formation of new blood vessels, thereby preventing necrosis of ischaemic tissue. Fucoidan also recruits stem cells from bone marrow, further accelerating tissue healing. The cellular and molecular mechanisms underlying fucoidan's effects on angiogenesis are then addressed, beginning with a brief overview of blood vessel formation. Recent advances have been made in understanding how the interactions between these polyfucoses and adult stem cells contribute to new blood vessel formation after ischaemic injury, notably via carbohydrates located mainly in the basement membrane and cell surface. 


\section{2- History of natural marine products}

Drug discovery based on naturally occurring molecules in general, and on natural marine products in particular, has been undergoing a renaissance in recent years [1]. The relative failure of combinatorial chemistry (synthesis)-based drug discovery has stimulated the interest of large pharmaceutical companies in natural products which, historically, have been the source of some $50 \%$ of all drugs. About $70 \%$ of Earth's surface is covered by the oceans, which are estimated to contain more than 2 million species, of which only 190000 have been identified so far [2]. Algal extracts have long been used for medicinal purposes, notably in Chinese traditional herbal medicine for at least two thousand years [3]. Some 400 species of seaweed are used as a source of food (especially in Asia and the Pacific region), feedstock, medicines, fertilizers and industrial raw materials. Some serve as vermifuges to expel ascarids, while others are used to cure sprains, rheumatism, goitre, cough, asthma and dropsy. Algae have also long been used in the prevention and treatment of cancer.

Polysaccharides are the main constituents of brown and red marine algae [4]. Seaweed cell walls are made up of various polysaccharides (cellulose, alginates, carrageenans and fucans, see box 1) and proteins. Carbohydrates, particularly those found on cell membranes, play critical biological roles. Defects in either the structure or the expression of carbohydrate-binding proteins are now known to play a role in an ever-increasing number of diseases, such as vascular disorders, viral and bacterial infections, tumour progression, and metastasis. Marine polysaccharides also display a wide variety of biological functions, such as extracellular matrix organization, cell growth and tissue maturation. Despite their potential for drug design, very few marine-derived carbohydrates are being developed commercially as therapeutics (see box 2). More attention has been paid to the structure and composition of these marine carbohydrates during the past 30 years, mainly because they form viscous gels in water that remain stable in the presence of many different additives [5,6]. Agar derived from the agarose found in the cell walls of red algae is used as a natural vegetable gelatine. It is also extensively used as a suspending agent for radiological solutions such as barium sulphate, and as a bulk laxative that forms a smooth and non-irritating hydrated bulk in the digestive tract. Agar is also used as an ingredient in tablets and capsules, in order to carry and release drugs, as well as in wound dressings and biomaterials. Alginate derivatives and carrageenans are widely used in toothpaste, soap, ice cream, yoghurt, tinned meat, fabric printing, and a host of other applications.

Research on fucoidans extracted from brown algae has steadily increased in recent years. Despite a wide range of biological activities and the lack of oral toxicity $[7,8]$, fucoidans remain relatively unexploited as a source of medicines, because of its heterogeneity. Indeed, it cannot yet be synthesized, and obtaining reproducible batches remains highly challenging. Although they have been commercially available for half a century, differences in their chemical composition and molecular weight between batches has limited pharmaceutical development. The international fucoidans market is none the less growing. 


\section{3- Peripheral arterial disease and cardiovascular risks - Treatments and unmet needs}

Peripheral arterial disease (PAD) is characterized by chronic obstruction of arteries that supply tissues. The affected tissues suffer from ischemia, and can develop necrosis if blood circulation is not quickly re-established, with a risk of losing a limb or its function. PAD is a frequent disease, affecting between $1 \%$ and $3 \%$ of people older than 60 years [9-12]. It results from atherosclerosis, thrombus formation or inflammatory processes, and develops in several stages. Critical limb ischemia (CLI) is the end-stage of PAD. Severe obstruction of blood flow results in ischemic pain at rest, ulcers, and a significant risk of limb loss. Epidemiological studies show that the incidence of PAD increases with age, up to $5 \%$ beyond 70 years. PAD progresses slowly, but $20 \%$ to $30 \%$ of patients eventually develop CLI (500-1000 per million inhabitants) requiring revascularization or amputation (more than 5000 cases yearly in France [13]). About 18\% of patients die during the year after CLI onset, and $26 \%$ require amputation. Surviving patients need special care that is both heavy and costly.

PAD affects the blood vessels supplying the arms and legs. Normal arteries are lined by a thin layer of endothelial cells (endothelium) which help to keep blood flowing. High blood pressure, smoking and high cholesterol can damage the endothelium and lead to the formation of atherosclerotic plaque or atheroma. The latter results from the invasion and accumulation of white blood cells, and proliferation of intimal-smooth muscle cells that create a "fibrofatty" plaque. This plaque can stay fixed to the artery wall and slowly grow, or may suddenly rupture, triggering platelet activation and aggregation on their exposed surface (Figure 2). Plaque rupture can add coronary artery or cerebrovascular disease to the underlying PAD.

Immobilization, chronic venous insufficiency, and venous blood stasis in the leg increase the risk of vein thrombosis associated with PAD [14]. Thrombus formation disrupts blood flow, leading to concerted interaction of activated endothelium with neutrophils and platelets, mediated mainly by P-selectin expression on endothelial cells.

Treatment is aimed at correcting the underlying causes of ischemia and at improving the vascularization of affected tissues, in order to prevent gangrene and limb loss, and to reduce the risk of heart attack and stroke $[9,15]$.

\subsection{Prevention of disease progression}

Treatment focuses first on modifiable risk factors such as hypertension, dyslipidemia and diabetes mellitus through lifestyle modifications $[9,10,15]$. Smoking cessation and exercise programs are proposed to alleviate symptoms. Drug treatment may be prescribed: 1) anticoagulants and/or antiplatelet/antithrombotic drugs (aspirin, clopidogrel) to prevent thrombus formation due to slow blood flow in microvessels [16]; 2) vasodilatory drugs to prevent platelet aggregation (patients with PAD have a systemic endothelial dysfunction associated with impaired vasodilation and enhanced platelet aggregation [17]; 3) antihypertensive drugs; and 4) cholesterol-lowering drugs [18]. There is a strong correlation between high low-density-lipoprotein cholesterol levels and PAD symptoms. 


\subsection{Anticoagulation}

Despite its disadvantages, heparin has been the polysaccharide most widely used to treat venous thrombosis for the past 70 years [19]. Heparin is a highly sulphated glycosaminoglycan: $80 \%$ of glucosamine residues are $\mathrm{N}$-sulphated, and $\mathrm{O}$-sulphate groups are more abundant than $\mathrm{N}$-sulphate groups. This mucopolysaccharide mainly exerts its anticoagulant activity by enhancing the inhibitory potency of the plasma proteins antithrombin (AT) and heparin cofactor II (HCII), which inhibit serine proteases involved in the coagulation pathway, such as thrombin and factor Xa [20]. The anticoagulant activity of heparin is due to a specific pentasaccharide sequence which binds with high affinity to AT [21].

\subsection{Surgical revascularization}

Between $40 \%$ and $60 \%$ of patients with CLI may need surgery to inject thrombolytic drugs (urokinase or rt-PA to dissolve a thrombus) or to bypass a blocked or narrowed artery with an artificial vessel to improve the microcirculation $[15,22]$. Balloon angioplasty and stenting are proposed to patients with short arterial occlusions, as a first-line attempt at limb salvage [22]. When surgical revascularization is not feasible, amputation is often the only therapeutic option. No available treatment has so far been shown to reduce the amputation rate at 6 month in patients with CLI [23].

\subsection{Novel therapies-therapeutic angiogenesis}

Much research is focused on ways of promoting the development of new blood vessels (therapeutic angiogenesis), including gene therapy [24-27] and cell therapy $[24,28,29]$. Despite encouraging phase 2 trials, however, large prospective double-blind trials of a genetic drug coding for a proangiogenic growth factor have shown little improvement in the risk of amputation or death $[9,15,27,30,31]$.

\subsubsection{Cell therapy}

Cell therapy, which is more promising, consists of local intramuscular injections of autologous bone marrow-derived mononuclear cells into the ischemic limb. Several randomized trials are underway to test the safety and efficacy of stem cells in the treatment of PAD [11,29,32-34].

\subsubsection{How do new blood vessels form?}

The formation of new blood vessels involves at least 3 distinct biological processes [35] (Figure 3). Angiogenesis refers to the formation of new vessels by "sprouting" from a pre-existing vascular network. Arteriogenesis refers to an increase in the wall thickness and luminal diameter of newly formed vessels via the recruitment of perivascular and smooth muscle cells. Vasculogenesis is the emergence of blood vessels de novo from vascular endothelial progenitor cells known as angioblasts, which differentiate into endothelial cells [36]. These three processes probably occur simultaneously during new vessel formation in the lower limbs of patients with PAD. Occlusion of an artery causes tissue hypoxia, which is a strong stimulus for angiogenesis [37]. Collateral vessels develop physiologically in these patients, leading to an increased microvessel density in affected muscles, 
which can partially compensate for occlusion of the artery but often fails to restore normal flow $[35,38]$.

The discovery in 1997 that adult peripheral blood contains circulating endothelial progenitor cells (EPCS) capable of differentiating into endothelial cells provided new insights into vascular biology and opened up exciting therapeutic vistas [39-42]. Asahara's team showed the contribution of these cells to blood vessel formation at sites of active angiogenesis, and obtained tissue regeneration by infusion of autologous EPCs after ischemic injury [43], leading to the concept of therapeutic angiogenesis [44]. These bone marrow-derived angiogenic cells are mobilized to the general circulation and then recruited to sites of ischemia in response to various stimuli produced by the local inflammatory response, including growth factors and cytokines such as vascular endothelial growth factor (VEGF), angiopoietin-1, granlulocyte/macrophage colony-stimulating factor (GM-CSF) and stromal-derived factor-1 (SDF-1, Figure 3). These angiogenic cells also participate in the development of new blood vessels by releasing factors that attract and activate pericytes and smooth-muscle cells, which in turn secrete soluble mediators that stimulate the migration and differentiation of local endothelial cells [45].

The ability of EPCs to mobilize and migrate to ischemic sites thus holds promise for this therapeutic approach $[41,46]$ (Figure 4). In animals, these immature cells can be mobilized from bone marrow into the circulation by treatment with a variety of compounds, including marine polysaccharides [4750], but this process becomes less efficient with age [51]. Reduced EPC numbers and functions are indicators of severe endothelial lesions in patients with PAD $[41,52,53]$.

Stem cells can be derived from bone marrow, peripheral blood or cord blood, but clinical applications have been hindered by ethical concerns and by difficulties in harvesting these cells or in safely and efficiently expanding them. Infusion of these bone marrow stem cells improved new blood vessel formation in animal models of PAD, enhancing collateral vessel formation and blood perfusion and permitting limb salvage even after complete vessel occlusion [39,41,42,54]. However, proangiogenic approaches have so far given disappointing results in patients with $\mathrm{CLI}$, owing partly to poor engraftment and limited differentiation/survival at the ischemic site $[9,11,15,51]$. Indeed, only a very small fraction of transplanted cells are incorporated into new vessels. EPCs isolated from peripheral blood of CLI patients have reduced proliferative capacity and increased apoptotic activity, and secrete only small amounts of VEGF.

\section{4- Chemistry}

\subsection{Extraction and preparation of low-molecular-weight fucoidan fractions}

Marine algae are immediately dried to reduce spoilage and chemical degradation, and are then stored at room temperature. Various extraction methods have been described [55-60]. Isolation and purification of fucans generally involves aqueous extraction (hot water, dilute acid (mainly hydrochloric or sulfuric acid ( $\mathrm{pH} 2.0)$ or alkalis), sometimes with extracting agents; fractional precipitation with ethanol, lead salts, calcium salts or quaternary ammonium salts; or fractionation 
on ion-exchange columns [58,61]. Partial fucan degradation may occur, especially at high temperatures and acidic $\mathrm{pH}$. Maceration with dilute hydrochloric acid or sulfuric acid removes any soluble mineral salts. Phenolic compounds can be removed by preheating with formaldehyde or by extraction at $\mathrm{pH}$ 6-7.

The extracts thus obtained contain other polysaccharides (laminaran and alginic acid) and lowmolecular-weight substances (colored materials, phenolic compounds, mannitol, D-glucose and, in some cases, myoinositol), as well as fucans of (ascophyllan and sargassan) [56,62]. Pretreatment with $80 \%$ aqueous ethanol before extraction can remove these low-molecular-weight compounds. Crude fractions are purified and fractionated with ethanol, ion-exchange chromatography, or gel-filtration chromatography. The purification yield varies with the $\mathrm{pH}$ of the extracting medium, the temperature, and the extraction time.

Low-molecular-weight fucoidan can then be obtained by acidic hydrolysis [59], or oxidative-reductive depolymerisation [63]. The oxidative-reductive process reduces the molecular weight (depolymerization) under mild conditions ( $\mathrm{pH} 7$, ambient temperature), with high yields.

\subsection{Structural determination}

Fucoidan being a natural product, it is necessary to ensure the characterization and reproducibility of the bioactive fraction, although small variations in chemical composition or molecular weight do not significantly affect its biological properties. The homogeneity of fucoidan preparations can be determined by gel filtration, ion-exchange chromatography and electrophoresis. Fucosidases and enzymes that degrade polyanionic polysaccharides are used to establish fucoidan structure and structure-activity relationships [64].

The type of fucoidan, its sulphation and molecular weight, and the conformation of its sugar residues all vary across seaweed species and with the period and place of their harvest $[56,57,65]$. Within a given species, the chemical composition of the fucoidan extract depends on the extraction conditions. Free fucans released upon cell wall isolation are similar in composition to fucoidan in Pelvetia canaliculata, Ascophyllum nodosum, Fucus vesiculosus and Laminaria digitate, and to sargassan in Sargassum muticum [66].

Fucoidan is mainly composed of $\alpha(1->3)$ and $\alpha(1->4)$ fucosyl units, usually sulphated at position 2 or 4 (rarely C3), with additional monosaccharides (D-xylose, D-galactose and D-mannose) $[55,56,67,68]$. Chevolot et al. reported that the predominant repeating structure of fucoidan from

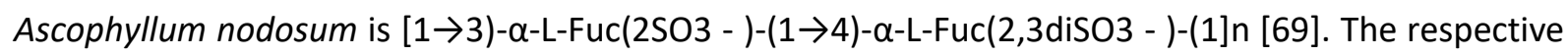
molar ratio of sulphate groups to total sugars (including uronic acid) is 3:2, suggesting that three moles of sulphate may be attached mainly to two fucose residues in the polysaccharides. 


\section{5- Biological properties}

\subsection{Marine polysaccharides exhibit anticoagulant activity}

Extracts from over 60 species of brown, red and green seaweed have been reported to exhibit anticoagulant capacity $[5,6,57]$. The main active components are sulphated polysaccharides [70], although not all sulphated carbohydrates possess anticoagulant activity $[56,71,72]$. Extracts of brown marine algae have higher anticoagulant activity than extracts of red and green marine algae.

\subsubsection{Principle of anticoagulation}

Anticoagulation is achieved mainly by inhibiting thrombin and factor $\mathrm{Xa}$, two serine proteases. This can be done by enhancing the activity of the main physiological serine protease inhibitors, namely antithrombin (AT) and heparin cofactor II (HClI). In vitro, heparin greatly accelerates the rate of thrombin inhibition both by AT and by HCII $[19,20]$. The mechanism of heparin-catalyzed thrombin inhibition by $\mathrm{AT}$ and $\mathrm{HCI}$ involves the formation of a ternary complex between heparin, proteinase inhibitor and proteinase [21].

\subsubsection{Marine polysaccharides have potent anticoagulant properties}

Carrageenans from red algae have been studied more extensively than fucans [57,73]. The mechanism of their anticoagulant activity does not involve AT. Even at high dilutions, they exhibit significant anticoagulant activity. However, their clinical use is limited by their immunogenicity and tendency to gel, due to their structural heterogeneity and very high molecular weight. Agar has similar properties [74].

\subsubsection{Fucoidan exhibits venous and arterial antithrombotic properties with no hemorrhagic risk}

In 1957 Springer et al reported that fucans extracted from the brown marine alga Fucus vesiculosus had anticoagulant activity in vitro and in vivo [58]. This activity was neutralized by protamine, showing the contribution of sulphate groups. Fucoidan was added to the group of heparinoids. The anticoagulant activity of fucoidan correlates with the chemical composition of the different fractions $[7,57,67,75]$. Anticoagulant activity is mainly related to a heparin-like effect on AT and $\mathrm{HCII}$, and to direct interaction with thrombin [76,77] (Figure 5). It correlates mainly with the molecular weight distribution, the sulphate group content and, probably, the structure of the fucoidan. The negative charge density of fucoidan is required for the expression of its antithrombin activity mediated by $\mathrm{HCll}$.

Fucoidan exhibits venous and arterial antithrombotic properties in experimental animals $[65,67,78]$ and, contrary to heparin, does not significantly increase the risk of bleeding. It increases the antithrombin activity of the protease nexin-1 (PN-1), a pericellular serpin expressed by vascular cells, and thereby significantly reduces circulating levels of thrombin by catalysing its inhibition [79]. Fucoidan also promotes fibrinolysis by potentiating plasminogen activators and reducing plasminogen activator inhibitor-1 (PAI-1) release by endothelial cells $[80,81]$. 


\subsection{Marine polysaccharides have angiogenic properties}

Several sulphated polysaccharides, including heparin, structural mimics of heparan sulphate, and carrageenans, have been found to inhibit angiogenesis in vitro, usually through a direct effect on endothelial cells when added to the experimental medium $[19,47,75]$. These properties are due in part to the capacity of these polyanions to bind to the heparin-binding site of proangiogenic growth factors (mainly VEGF and basic fibroblast growth factor (FGF2)) via their sulphate groups. Commercial high-molecular-weight (HMW) fucoidan reduced neovascularization and suppressed tumour angiogenesis in experimental models by triggering endothelial cell apoptosis [68]. These effects are related to both the sulphation ratio and the molecular weight.

\subsubsection{Contrary to other polysaccharides, fucoidan potentiates angiogenesis in vitro and in vivo}

Fucoidan pretreatment of cultured human umbilical vein endothelial cells (HUVEC) or EPCs for 36 to 72 hours enhances FGF-2-dependent angiogenesis in vitro [82,83], while the addition of fucoidan directly to the culture medium inhibits growth-factor-induced vascular tube formation by endothelial cells $[47,84]$. Fucoidan prestimulation enhances various angiogenic processes, namely cell recruitment to ischemic tissue via enhanced EPC adhesion to activated endothelium; MMP-9 metalloproteinase secretion; extravasation; and differentiation into a vascular network (Figure 6). The beneficial effect of EPC infusion in a mouse model of hindlimb ischemia was significantly amplified by fucoidan stimulation, preventing tissue necrosis [85] (Figure 7). Fucoidan can also promote new blood vessel formation when infused intramuscularly, either alone or together with the proangiogenic growth factor FGF-2 [86]. Fucoidan induced an $87 \%$ reduction in necrosis and a $75 \%$ improvement in muscle preservation on day 14, as compared to saline alone [85]. Intravenous fucoidan infusion had protective effects in rat models of myocardial ischemia [87]. This protection was associated with enhanced neoangiogenesis and a reduction in rhabdomyolysis. During ischemia, muscle destruction causes permeabilization of muscle fibres and the release of their contents, including enzymes such as CPK, into the bloodstream. Bolus administration of fucoidan induced a $70 \%$ reduction in CPK activity as compared with normal saline. None of the mice treated with fucoidan presented necrosis of the fingers or legs, contrary to saline-treated controls [85].

Fucoidan also inhibits smooth muscle cell proliferation in vitro [88,89] and in vivo [90,91]. Its injection prevented neointima formation in an injured thoracic aorta rat model, and after stenting in the rabbit iliac artery angioplasty model. Fucoidan stimulated the formation of an endothelial cell lining in vascular allografts after 1 month of treatment [92]. Injection of crude heparin and LMW heparin in the same experimental conditions did not induce angiogenesis $[47,86]$.

\subsubsection{Injections of LMW fucoidan induce rapid mobilization of stem cells from bone marrow}

Intraperitoneal (IP) or intramuscular injections of LMW fucoidan $(5 \mathrm{mg} / \mathrm{kg} /$ day) induce rapid mobilization of immature progenitors from bone marrow, about as potently as VEGF $(0.5 \mu \mathrm{g} / \mathrm{kg} / \mathrm{day})$ [47]. Circulating numbers of progenitor cells are significantly increased in peripheral blood of fucoidan-treated animals. Stem cell mobilization is also observed after oral fucoidan ingestion $[7,93]$. 
This mobilization correlates with the release of GAG-bound SDF-1 from its tissue storage sites into the circulation on fucoidan administration.

Tissue ischemia is accompanied by inflammation, and fucoidan has been shown to possess antiinflammatory properties $[7,56,67,94]$. Daily subcutaneous injection of fucoidan protected parenchymal tissue against inflammatory processes and myofibroblastic remodelling in a rat cardiac allograft model [95]. It reduced neutrophil, macrophage and CD4+ $T$ cell infiltration at sites of inflammation, and improved myocardial status after ischemia/reperfusion injury [7]. These antiinflammatory activities correlated with a reduction in tissue expression of transforming growth factor beta (TGF $\beta$ ) and IL-10. Fucoidan down-regulated the expression of inducible iNOS (that inhibits nitric oxide production) and cyclooxygenase 2 (COX2) protein and mRNA levels.

\subsection{What is the fucoidan mechanism of action?}

\subsubsection{Cellular and molecular mechanisms underlying fucoidan proangiogenic activity}

The effects of fucoidan appear to be mediated mainly by its charge density, molecular weight and degree of sulphation, rather than by a specific carbohydrate structure [69]. Fucoidan shares several characteristics with HSPGs. The structural requirements for its interaction with coagulation factors and target proteases depend on the proportions and/or distribution of sulphated groups along the fucose backbone, and on the saccharide chain composition [96]. Fucoidan fractions presenting slight differences in their sulphation pattern differ in their anticoagulant and antithrombotic activities $[65,97]$. Sulphation is critical for fucoidan activity, but sulphate groups alone are unlikely to be responsible for the observed biological properties. The fucosyl backbone may also be important. Fucosylated chondroitin sulphate species, made up of alternating $\beta$-D-glucuronic acid and $\mathrm{N}$-acetyl- $\beta$ D-galactosamine units with branches of sulphated fucose, enhance FGF-2-induced tubular morphogenesis in vitro and also trigger an increase in blood SDF-1 levels and immature cell mobilization. Like fucoidan, these chondroitin sulphate species that bear sulphated fucose chains express antithrombotic activity in experimental animals with venous and arterial thrombosis. Branched sulphated fucoses are the key motif responsible for this activity, as shown by comparing native and chemically modified defucosylated and/or desulphated chondroitins. The number of sulphate groups, and the nature of the molecular backbone, significantly influence the biological properties of these compounds [96].

\subsubsection{Fucoidan modulates the biological activity of angiogenic heparin-binding proteins}

Of particular interest, fucoidan partially restores the adhesion of cultured progenitor cells to activated endothelium after their treatment with enzymes that remove HSPGs from the cell surface [85]. Owing to its ionic structure, fucoidan mimics some properties of GAGs and can bind and modulate the activity of a large number of proteins, including proteases, cytokines and growth factors. As a result, fucoidan affects many biological activities in vitro, including coagulation, inflammation, viral infection, fertilization, and angiogenesis $[7,56,68,98]$. 


\subsubsection{Fucoidan may act as a direct growth-factor signal transducer}

The proangiogenic activity of fucoidan is linked to its direct interaction with cell membranes. Fucoidan binds to the EPC outer membrane at displaceable binding sites, and is then internalized by endocytosis. There it can enhance local angiogenesis through the transduction of intracellular signals required to induce the proangiogenic phenotype. Endothelial cell surface-bound fucoidan could also act as a coreceptor for angiogenic growth factors. The putative fucoidan receptor function might involve a carbohydrate-binding domain that interacts with the fucoidan carbohydrate backbone. Fucoidan might thus interact with macrophage TLR4 and SR receptors that recognize carbohydrate structures [99]. Its binding to these receptors induces several signal transduction events (p38, MAPK, ERK1/2 and SAPK/JNK activation) that lead to macrophage activation. Because of its spatial structure, fucoidan can mimic the clustering of sulphated, sialylated and fucosylated oligosaccharides on the cell surface and can provide the appropriate structural backbone to bind selectins with high affinity $[100,101]$. Fucoidan is also able to interact with other receptors on the cell membrane, such as CD44 (hyaluronic acid receptor), $\alpha_{M}$ (CD11b), $\beta_{2}(C D 18)$ and even $\alpha_{M} \beta_{2}$ (macrophage antigen-1 (Mac-1)) [85].

Fucoidan binds to the cell membrane and can thereby induce cellular responses analogous to signal transduction by growth factors. It is thus able to modulate the expression of genes involved at different stages of neovessel formation, such as cell migration, cytoskeleton organization, cell mobilization, and homing [102].

Pseudotube formation induced by fucoidan correlates in vitro with overexpression of the $\alpha 6$ integrin subunit on the endothelial cell surface $[83,102]$. This $\alpha 6$ overexpression results from transcriptional upregulation. The integrin $\alpha 6$ chain, when assembled with integrin $\beta 1$ or $\beta 4$ subunits, forms major receptors for laminin. Several results show that $\alpha 6$ integrins function in vivo as homing receptors for haematopoietic stem cells and progenitor cells $[103,104]$. The same integrins also promote vascular repair. The effect of fucoidan on $\alpha 6$ expression on the cell membrane would strongly enhance stem cell migration and mobilization in vivo. HSPGs can transduce extracellular signals in a manner analogous to signal transduction by growth factor receptors. Fucoidan may act as a direct signal transducer. It is conceivable that membrane-bound fucoidan may participate directly in signal transduction in response to growth factor binding, by interacting directly with its receptors. The idea that coreceptors may act as signalling molecules independently of their role as receptor binding partners is beginning to gain ground.

\subsection{How does fucoidan act in vivo?}

In vivo, fucoidan can bind to numerous proteins. Fucoidan actively modulates coagulation and can reduce circulating levels of thrombin by catalysing its inhibition $[7,56,57,67,70,75,77]$. Lower thrombin generation would attenuate thrombus formation, thereby enabling macrophages and EPCs to migrate to the lesion and ensure reperfusion. GAGs have a crucial role in mediating stem cell recruitment and homing to ischemic tissues. GAGs play a key role in sequestering a variety of 
proteins that regulate the proliferation, differentiation and trafficking of stem cells between bone marrow and peripheral blood.

Several lines of evidence suggest that fucoidan acts through SDF-1. Intramuscular fucoidan injections increase plasma levels of SDF-1 and thus promote stem cell mobilization $[47,49,86]$. SDF- 1 is anchored to HSPGs present at the surface of stromal cells and endothelial cells, and on the ECM. Fucoidan can specifically displace sequestered SDF-1 from its HSPG anchors on the endothelial surface and thereby contribute to its release into the circulation. According to Sweeney, the amount of SDF-1 thus released into the circulation is sufficient to trigger the observed cell mobilization [49]. In addition to SDF-1, levels of other chemokines (IL-6, IL-8) and cytokines (granulocyte CSF, macrophage CSF) are also increased after fucoidan treatment, possibly owing to their release from HSPGs.

In his excellent review of sulphated fucans and galactans, Pomin forwards a mechanism to explain the antiinflammatory properties of marine polysaccharides that could also account for the impact of fucoidan on EPC recruitment [105]. The molecular mechanisms behind these proangiogenic properties would involve (Figure 8): i) impaired binding of stem cells to the endothelium via fucoidan binding to $\mathrm{P}$ - and/or L-selectins which play a central role in the inflammatory response triggered by ischemia ( $P$-selectin is upregulated on endothelial cells and platelets during ischemic disorders) $[102,106]$ and, most likely, ii) disruption of the SDF-1 gradient between blood and bone marrow or ischemic tissue. This would modify the chemokine gradient that sustains the homing of stem cells/leukocytes to ischemic sites and promotes their mobilization. In addition to the contribution of EPCS to new vessel formation, enhanced SDF-1 expression, which can activate EPCs, may also contribute to revascularization of ischemic tissues [54]. This would also explain the impact of fucoidan on intimal growth after stenting in rabbits and after allogeneic vascular transplantation in mice $[78,92]$. Fucoidan can also act on surrounding cells such as smooth muscle cells, neutrophils and macrophages attracted by cytokines released from an ischemic site [107].

During transmigration through the endothelium, progenitors traverse the endothelial cell monolayer and the subendothelial basement membrane. Consequently, transmigrating cells interact with endothelial cells, GAGs and EMC adhesion proteins. Integrin $\alpha 6$, a laminin receptor involved in stem cell homing to bone marrow [104], is expressed by EPCs. Its expression is required for stem cell migration, and its overexpression after fucoidan treatment might facilitate their homing towards ischemic sites. Finally, adhesion receptors like selectins are important for cell migration and extravasation to ischemic sites. During mobilization, traffic between bone marrow and blood is bidirectional. According to Frenette et al., blockade of endothelial selectins may prevent progenitors from re-entering bone marrow [48].

\section{6- Conclusion}

Development of a therapy capable of preventing tissue necrosis and of favouring revascularization is crucial for patients with critical ischemia [108]. Although marine polysaccharides have numerous interesting effects on coagulation, thrombosis, inflammation and angiogenesis, their clinical 
development is hindered by their heterogeneity. Fucoidan is systemically distributed after ingestion or intravenous injection and is non toxic in mice when injected at doses exceeding $1 \mathrm{~g} / \mathrm{kg}$ (private communication). Oral ingestion of fucoidan at doses of 1 to $3 \mathrm{~g} /$ day for up to 3 months is non toxic in healthy volunteers $[93,109]$.

Cardiovascular disease is the leading cause of death worldwide (17.3 million deaths each year, representing $30 \%$ of global mortality), and new anticoagulants are urgently needed. LMW fucoidans possess several important advantages as alternative anticoagulant and proangiogenic therapies. First and foremost, they are devoid of significant pro-haemorrhagic effects. Second, because of their nonmammalian origin, there is no risk of contamination with viruses or unconventional pathogens such as the prion responsible for bovine spongiform encephalopathy. Third, as byproducts of alginate preparation for the food and cosmetics industries, they represent a cheap and readily available source of new biologically active molecules. A better understanding of the mechanisms by which these polysaccharides promote EPC activation and recruitment to ischemic sites is necessary for optimal development of a proangiogenic therapy product.

\section{7- References}

1. Kiuru, P., D'Auria, M.V., Muller, C.D., et al. (2014) Exploring marine resources for bioactive compounds. Planta Med., 80 (14), 1234-1246.

2. Penesyan, A., Kjelleberg, S., and Egan, S. (2010) Development of novel drugs from marine surface associated microorganisms. Mar. Drugs, 8 (3), 438-459.

3. Tseng, C.K., and Chang, C.F. (1984) Chinese seaweeds in herbal medicine. Hydrobiologia, 116 (1), 152-154.

4. Guiry M.D. http://www.seaweed.ie/nutrition/index.php (22 July 2016) The Seaweed Site: information on marine algae.

5. Ruocco, N., Costantini, S., Guariniello, S., and Costantini, M. (2016) Polysaccharides from the Marine Environment with Pharmacological, Cosmeceutical and Nutraceutical Potential. Mol. Basel Switz., 21 (5).

6. Zaporozhets, T., and Besednova, N. (2016) Prospects for the therapeutic application of sulfated polysaccharides of brown algae in diseases of the cardiovascular system: review. Pharm. Biol., 1-10.

7. Fitton, J.H., Stringer, D.N., and Karpiniec, S.S. (2015) Therapies from Fucoidan: An Update. Mar. Drugs, 13 (9), 5920-5946.

8. Hwang, P.-A., Yan, M.-D., Lin, H.-T.V., et al. (2016) Toxicological Evaluation of Low Molecular Weight Fucoidan in Vitro and in Vivo. Mar. Drugs, 14 (7).

9. Norgren, L., Hiatt, W.R., Dormandy, J.A., et al. (2007) Inter-Society Consensus for the Management of Peripheral Arterial Disease (TASC II). J. Vasc. Surg., 45 Suppl S, S5-67.

10. Lau, J.F., Weinberg, M.D., and Olin, J.W. (2011) Peripheral artery disease. Part 1: clinical evaluation and noninvasive diagnosis. Nat. Rev. Cardiol., 8 (7), 405-418.

11. Raval, Z., and Losordo, D.W. (2013) Cell therapy of peripheral arterial disease: from experimental findings to clinical trials. Circ. Res., 112 (9), 1288-1302.

12. Dua, A., and Lee, C.J. (2016) Epidemiology of Peripheral Arterial Disease and Critical Limb Ischemia. Tech. Vasc. Interv. Radiol., 19 (2), 91-95.

13. http://www.fedecardio.org/votre-coeur/maladies/arteriopathie-obliterante (17 july 2016) Artériopathie oblitérante. 
14. Esmon, C.T. (2009) Basic mechanisms and pathogenesis of venous thrombosis. Blood Rev., 23 (5), 225-229.

15. Weinberg, M.D., Lau, J.F., Rosenfield, K., and Olin, J.W. (2011) Peripheral artery disease. Part 2: medical and endovascular treatment. Nat. Rev. Cardiol., 8 (8), 429-441.

16. Foley, T.R., Waldo, S.W., and Armstrong, E.J. (2016) Antithrombotic therapy in peripheral artery disease. Vasc. Med. Lond. Engl., 21 (2), 156-169.

17. Martin, B.-J., and Anderson, T.J. (2009) Risk prediction in cardiovascular disease: the prognostic significance of endothelial dysfunction. Can. J. Cardiol., 25 Suppl A, 15A-20A.

18. Sharma, S., Thapa, R., Jeevanantham, V., et al. (2014) Comparison of lipid management in patients with coronary versus peripheral arterial disease. Am. J. Cardiol., 113 (8), 1320-1325.

19. Oduah, E.I., Linhardt, R.J., and Sharfstein, S.T. (2016) Heparin: Past, Present, and Future. Pharm. Basel Switz., 9 (3).

20. Rosenberg, R.D., and Damus, P.S. (1973) Correlation between structure and function of heparin. J. Biol. Chem., 248, 6490-6495.

21. Choay, J., Petitou, M., Lormeau, J.C., et al. (1983) Structure-activity relationship in heparin: a synthetic pentasaccharide with high affinity for antithrombin III and eliciting high anti-factor Xa activity. Biochem. Biophys. Res. Commun., 116 (2), 492-499.

22. Klein, A.J., and Ross, C.B. (2016) Endovascular treatment of lower extremity peripheral arterial disease. Trends Cardiovasc. Med.

23. Rooke, T.W., Hirsch, A.T., Misra, S., et al. (2012) 2011 ACCF/AHA focused update of the guideline for the management of patients with peripheral artery disease (updating the 2005 guideline): a report of the American College of Cardiology Foundation/American Heart Association Task Force on Practice Guidelines: developed in collaboration with the Society for Cardiovascular Angiography and Interventions, Society of Interventional Radiology, Society for Vascular Medicine, and Society for Vascular Surgery. Catheter. Cardiovasc. Interv. Off. J. Soc. Card. Angiogr. Interv., 79 (4), 501-531.

24. Collinson, D.J., and Donnelly, R. (2004) Therapeutic angiogenesis in peripheral arterial disease: can biotechnology produce an effective collateral circulation? Eur. J. Vasc. Endovasc. Surg. Off. J. Eur. Soc. Vasc. Surg., 28 (1), 9-23.

25. Rissanen, T.T., and Ylä-Herttuala, S. (2007) Current status of cardiovascular gene therapy. Mol. Ther. J. Am. Soc. Gene Ther., 15 (7), 1233-1247.

26. Pasqualoni, E., Messas, E., Fiessinger, J.-N., and Emmerich, J. (2008) [Treatment perspectives for critical limb ischemia: gene and cell therapy]. Presse Médicale Paris Fr. 1983, 37 (6 Pt 2), 10391046.

27. Kibbe, M.R., Hirsch, A.T., Mendelsohn, F.O., et al. (2016) Safety and efficacy of plasmid DNA expressing two isoforms of hepatocyte growth factor in patients with critical limb ischemia. Gene Ther., 23 (4), 399.

28. Emmerich, J. (2005) Current state and perspective on medical treatment of critical leg ischemia: gene and cell therapy. Int. J. Low. Extrem. Wounds, 4 (4), 234-241.

29. Cooke, J.P., and Losordo, D.W. (2015) Modulating the vascular response to limb ischemia: angiogenic and cell therapies. Circ. Res., 116 (9), 1561-1578.

30. Shyu, K.-G., Chang, H., Wang, B.-W., and Kuan, P. (2003) Intramuscular vascular endothelial growth factor gene therapy in patients with chronic critical leg ischemia. Am. J. Med., 114 (2), 85-92.

31. Baumgartner, I., Chronos, N., Comerota, A., et al. (2009) Local gene transfer and expression following intramuscular administration of FGF-1 plasmid DNA in patients with critical limb ischemia. Mol. Ther. J. Am. Soc. Gene Ther., 17 (5), 914-921.

32. Lawall, H., Bramlage, P., and Amann, B. (2011) Treatment of peripheral arterial disease using stem and progenitor cell therapy. J. Vasc. Surg., 53 (2), 445-453.

33. Liang, T.W., Jester, A., Motaganahalli, R.L., et al. (2016) Autologous bone marrow mononuclear cell therapy for critical limb ischemia is effective and durable. J. Vasc. Surg., 63 (6), 1541-1545. 
34. Ai, M., Yan, C.-F., Xia, F.-C., et al. (2016) Safety and efficacy of cell-based therapy on critical limb ischemia: A meta-analysis. Cytotherapy, 18 (6), 712-724.

35. Carmeliet, P. (2003) Angiogenesis in health and disease. Nat. Med., 9 (6), 653-660.

36. Asahara, T., Masuda, H., Takahashi, T., et al. (1999) Bone marrow origin of endothelial progenitor cells responsible for postnatal vasculogenesis in physiological and pathological neovascularization. Circ. Res., 85 (3), 221-228.

37. Ho, T.K., Abraham, D.J., Black, C.M., and Baker, D.M. (2006) Hypoxia-inducible factor 1 in lower limb ischemia. Vascular, 14 (6), 321-327.

38. Ho, T.K., Rajkumar, V., Ponticos, M., et al. (2006) Increased endogenous angiogenic response and hypoxia-inducible factor-1alpha in human critical limb ischemia. J. Vasc. Surg., 43 (1), 125133.

39. Badorff, C., and Dimmeler, S. (2006) Neovascularization and cardiac repair by bone marrowderived stem cells. Handb. Exp. Pharmacol., (174), 283-298.

40. Critser, P.J., and Yoder, M.C. (2010) Endothelial colony-forming cell role in neoangiogenesis and tissue repair. Curr. Opin. Organ Transplant., 15 (1), 68-72.

41. Asahara, T., Kawamoto, A., and Masuda, H. (2011) Concise review: Circulating endothelial progenitor cells for vascular medicine. Stem Cells Dayt. Ohio, 29 (11), 1650-1655.

42. Grisar, J.C., Haddad, F., Gomari, F.A., and Wu, J.C. (2011) Endothelial progenitor cells in cardiovascular disease and chronic inflammation: from biomarker to therapeutic agent. Biomark. Med., 5 (6), 731-744.

43. Asahara, T., Murohara, T., Sullivan, A., et al. (1997) Isolation of putative progenitor endothelial cells for angiogenesis. Science, 275 (5302), 964-967.

44. Pearson, J.D. (2009) Endothelial progenitor cells - hype or hope? J. Thromb. Haemost. JTH, 7 (2), 255-262.

45. Silvestre, J.-S., Smadja, D.M., and Lévy, B.I. (2013) Postischemic revascularization: from cellular and molecular mechanisms to clinical applications. Physiol. Rev., 93 (4), 1743-1802.

46. Chavakis, E., Urbich, C., and Dimmeler, S. (2008) Homing and engraftment of progenitor cells: a prerequisite for cell therapy. J. Mol. Cell. Cardiol., 45 (4), 514-522.

47. Boisson-Vidal, C., Zemani, F., Caligiuri, G., et al. (2007) Neoangiogenesis induced by progenitor endothelial cells: effect of fucoidan from marine algae. Cardiovasc. Hematol. Agents Med. Chem., 5 (1), 67-77.

48. Frenette, P.S., and Weiss, L. (2000) Sulfated glycans induce rapid hematopoietic progenitor cell mobilization: evidence for selectin-dependent and independent mechanisms. Blood, 96 (7), 2460-2468.

49. Sweeney, E.A., Lortat-Jacob, H., Priestley, G.V., et al. (2002) Sulfated polysaccharides increase plasma levels of SDF-1 in monkeys and mice: involvement in mobilization of stem/progenitor cells. Blood, 99 (1), 44-51.

50. Roux, N., Brakenhielm, E., Freguin-Bouillant, C., et al. (2012) Progenitor cell mobilizing treatments prevent experimental transplant arteriosclerosis. J. Surg. Res., 176 (2), 657-665.

51. Dimmeler, S., and Leri, A. (2008) Aging and disease as modifiers of efficacy of cell therapy. Circ. Res., 102 (11), 1319-1330.

52. Oda, M., Toba, K., Kato, K., et al. (2012) Hypocellularity and insufficient expression of angiogenic factors in implanted autologous bone marrow in patients with chronic critical limb ischemia. Heart Vessels, 27 (1), 38-45.

53. Bitterli, L., Afan, S., Bühler, S., et al. (2016) Endothelial progenitor cells as a biological marker of peripheral artery disease. Vasc. Med. Lond. Engl., 21 (1), 3-11.

54. Zemani, F., Silvestre, J.-S., Fauvel-Lafeve, F., et al. (2008) Ex vivo priming of endothelial progenitor cells with SDF-1 before transplantation could increase their proangiogenic potential. Arterioscler. Thromb. Vasc. Biol., 28 (4), 644-650.

55. Chevolot, L., Foucault, A., Chaubet, F., et al. (1999) Further data on the structure of brown seaweed fucans: relationships with anticoagulant activity. Carbohydr. Res., 319 (1-4), 154-165. 
56. Ale, M.T., Mikkelsen, J.D., and Meyer, A.S. (2011) Important determinants for fucoidan bioactivity: a critical review of structure-function relations and extraction methods for fucosecontaining sulfated polysaccharides from brown seaweeds. Mar. Drugs, 9 (10), 2106-2130.

57. Boisson-Vidal, C., Colliec-Jouault, S., Fischer, A.M., et al. (1991) Biological activities of fucans extracted from brown seaweeds. Drugs Future, 16 (6), 539-545.

58. Springer, G.F., Wurzel, H.A., Mcneal, G.M., et al. (1957) Isolation of anticoagulant fractions from crude fucoidin. Proc. Soc. Exp. Biol. Med. Soc. Exp. Biol. Med. N. Y. N, 94 (2), 404-409.

59. Colliec, S., Boisson Vidal, C., and Jozefonvicz, J. (1994) A low molecular weight fucoidan fraction from the brown seaweed Pelvetia canaliculata. Phytochemistry, 35 (3), 697-700.

60. Percival, E.G.V., and Ross, A.G. (1950) Fucoidin. Part I. The isolation and purification of fucoidin from brown seaweeds. J. Chem. Soc., 717-720.

61. Pauw, N., and Persoone, G. (1988) Microalgae for aquaculture, in Micro-algal Biotechnology, Borowitzka, M.A., Borowitzka, L.J., Cambridge University Press, Cambridge, UK, pp. 197-221.

62. Deniaud-Bouët, E., Kervarec, N., Michel, G., et al. (2014) Chemical and enzymatic fractionation of cell walls from Fucales: insights into the structure of the extracellular matrix of brown algae. Ann. Bot., 114 (6), 1203-1216.

63. Nardella, A., Chaubet, F., Boisson-Vidal, C., et al. (1996) Anticoagulant low molecular weight fucans produced by radical process and ion exchange chromatography of high molecular weight fucans extracted from the brown seaweed Ascophyllum nodosum. Carbohydr. Res., 289, 201208.

64. Berteau, O., McCort, I., Goasdoué, N., et al. (2002) Characterization of a new alpha-L-fucosidase isolated from the marine mollusk Pecten maximus that catalyzes the hydrolysis of alpha-Lfucose from algal fucoidan (Ascophyllum nodosum). Glycobiology, 12 (4), 273-282.

65. Boisson Vidal, C., Chaubet, F., Chevolot, L., et al. (2000) Relationship between antithrombotic activities of fucans and their structure. Drug Dev. Res., 51, 216-224.

66. Kloareg, B., and Quatrano, R.S. (1988) Structure of the cells walls of marine algae and ecophysiological functions of the matrix polysaccharides. Oceanogr. Mar. Biol. Annu. Rev., 26, 259-315.

67. Li, B., Lu, F., Wei, X., and Zhao, R. (2008) Fucoidan: structure and bioactivity. Mol. Basel Switz., 13 (8), 1671-1695.

68. Ustyuzhanina, N.E., Bilan, M.I., Ushakova, N.A., et al. (2014) Fucoidans: Pro- or antiangiogenic agents? Glycobiology, 24 (12), 1265-1274.

69. Chevolot, L., Mulloy, B., Ratiskol, J., et al. (2001) A disaccharide repeat unit is the major structure in fucoidans from two species of brown algae. Carbohydr. Res., 330 (4), 529-535.

70. McLellan, D.S., and Jurd, K.M. (1992) Anticoagulants from marine algae. Blood Coagul. Fibrinolysis Int. J. Haemost. Thromb., 3 (1), 69-77.

71. Casu, B., Oreste, P., Torri, G., et al. (1981) The structure of heparin oligosaccharide fragments with high anti-(factor $\mathrm{Xa}$ ) activity containing the minimal antithrombin III-binding sequence Chemical and13C nuclear-magnetic-resonance studies. Biochem. J., 197 (3), 599-609.

72. Lindahl, U., Bäckström, G., Thunberg, L., and Leder, I.G. (1980) Evidence for a 3-O-sulfated Dglucosamine residue in the antithrombin-binding sequence of heparin. Proc. Natl. Acad. Sci. U. S. A., 77 (11), 6551-6555.

73. de Jesus Raposo, M.F., de Morais, A.M.B., and de Morais, R.M.S.C. (2015) Marine polysaccharides from algae with potential biomedical applications. Mar. Drugs, 13 (5), 29673028.

74. Elsner, H., Broser, W., and Burgel, E. (1937) The presence of highly active anticoagulants in red algae. Z. Physiol. Chem., 246, 244-249.

75. Cumashi, A., Ushakova, N.A., Preobrazhenskaya, M.E., et al. (2007) A comparative study of the anti-inflammatory, anticoagulant, antiangiogenic, and antiadhesive activities of nine different fucoidans from brown seaweeds. Glycobiology, 17 (5), 541-552. 
76. Church, F.C., Meade, J.B., Treanor, R.E., and Whinna, H.C. (1989) Antithrombin activity of fucoidan. The interaction of fucoidan with heparin cofactor II, antithrombin III, and thrombin. $J$. Biol. Chem., 264 (6), 3618-3623.

77. Colliec, S., Fischer, A.M., Tapon-Bretaudiere, J., et al. (1991) Anticoagulant properties of a fucoïdan fraction. Thromb. Res., 64 (2), 143-154.

78. Durand, E., Helley, D., Al Haj Zen, A., et al. (2008) Effect of low molecular weight fucoidan and low molecular weight heparin in a rabbit model of arterial thrombosis. J. Vasc. Res., 45 (6), 529-537.

79. Richard, B., Bouton, M.-C., Loyau, S., et al. (2006) Modulation of protease nexin-1 activity by polysaccharides. Thromb. Haemost., 95 (2), 229-235.

80. Doctor, V.M., Hill, C., and Jackson, G.J. (1995) Effect of fucoidan during activation of human plasminogen. Thromb. Res., 79 (3), 237-247.

81. Chabut, D., Fischer, A.M., Helley, D., and Colliec, S. (2004) Low molecular weight fucoidan promotes FGF-2-induced vascular tube formation by human endothelial cells, with decreased PAI-1 release and ICAM-1 downregulation. Thromb. Res., 113 (1), 93-95.

82. Matou, S., Helley, D., Chabut, D., et al. (2002) Effect of fucoidan on fibroblast growth factor-2induced angiogenesis in vitro. Thromb. Res., 106 (4-5), 213-221.

83. Zemani, F., Benisvy, D., Galy-Fauroux, I., et al. (2005) Low-molecular-weight fucoidan enhances the proangiogenic phenotype of endothelial progenitor cells. Biochem. Pharmacol., 70 (8), $1167-1175$.

84. Soeda, S., Kozako, T., Iwata, K., and Shimeno, H. (2000) Oversulfated fucoidan inhibits the basic fibroblast growth factor-induced tube formation by human umbilical vein endothelial cells: its possible mechanism of action. Biochim. Biophys. Acta, 1497 (1), 127-134.

85. Sarlon, G., Zemani, F., David, L., et al. (2012) Therapeutic effect of fucoidan-stimulated endothelial colony-forming cells in peripheral ischemia. J. Thromb. Haemost. JTH, 10 (1), 38-48.

86. Luyt, C.-E., Meddahi-Pellé, A., Ho-Tin-Noe, B., et al. (2003) Low-molecular-weight fucoidan promotes therapeutic revascularization in a rat model of critical hindlimb ischemia. $J$. Pharmacol. Exp. Ther., 305 (1), 24-30.

87. Omata, M., Matsui, N., Inomata, N., and Ohno, T. (1997) Protective effects of polysaccharide fucoidin on myocardial ischemia-reperfusion injury in rats. J. Cardiovasc. Pharmacol., 30 (6), 717-724.

88. Logeart, D., Prigent-Richard, S., Boisson-Vidal, C., et al. (1997) Fucans, sulfated polysaccharides extracted from brown seaweeds, inhibit vascular smooth muscle cell proliferation. II. Degradation and molecular weight effect. Eur. J. Cell Biol., 74 (4), 385-390.

89. Patel, M.K., Mulloy, B., Gallagher, K.L., et al. (2002) The antimitogenic action of the sulphated polysaccharide fucoidan differs from heparin in human vascular smooth muscle cells. Thromb. Haemost., 87 (1), 149-154.

90. Deux, J.-F., Meddahi-Pellé, A., Le Blanche, A.F., et al. (2002) Low molecular weight fucoidan prevents neointimal hyperplasia in rabbit iliac artery in-stent restenosis model. Arterioscler. Thromb. Vasc. Biol., 22 (10), 1604-1609.

91. Hlawaty, H., Suffee, N., Sutton, A., et al. (2011) Low molecular weight fucoidan prevents intimal hyperplasia in rat injured thoracic aorta through the modulation of matrix metalloproteinase-2 expression. Biochem. Pharmacol., 81 (2), 233-243.

92. Freguin-Bouilland, C., Alkhatib, B., David, N., et al. (2011) Syngeneic bone marrow cell therapy prevents intimal proliferation in allogeneic vascular transplantation. J. Surg. Res., 168 (1), 143148.

93. Irhimeh, M.R., Fitton, J.H., and Lowenthal, R.M. (2007) Fucoidan ingestion increases the expression of CXCR4 on human CD34+ cells. Exp. Hematol., 35 (6), 989-994.

94. Blondin, C., Fischer, E., Boisson-Vidal, C., et al. (1994) Inhibition of complement activation by natural sulfated polysaccharides (fucans) from brown seaweed. Mol. Immunol., 31 (4), 247253. 
95. Alkhatib, B., Freguin-Bouilland, C., Lallemand, F., et al. (2006) Low molecular weight fucan prevents transplant coronaropathy in rat cardiac allograft model. Transpl. Immunol., 16 (1), 1419.

96. Pomin, V.H., and Mourão, P.A.S. (2008) Structure, biology, evolution, and medical importance of sulfated fucans and galactans. Glycobiology, 18 (12), 1016-1027.

97. Fonseca, R.J.C., Oliveira, S.-N.M.C.G., Melo, F.R., et al. (2008) Slight differences in sulfation of algal galactans account for differences in their anticoagulant and venous antithrombotic activities. Thromb. Haemost., 99 (3), 539-545.

98. Boisson Vidal, C., Haroun-Bouhedja, F., Ellouali, M., et al. (1995) biological activities of polysaccharides from marine algae. Drugs Future, 20 (12), 1237-1249.

99. Teruya, T., Tatemoto, H., Konishi, T., and Tako, M. (2009) Structural characteristics and in vitro macrophage activation of acetyl fucoidan from Cladosiphon okamuranus. Glycoconj. J., 26 (8), 1019-1028.

100. Bachelet, L., Bertholon, I., Lavigne, D., et al. (2009) Affinity of low molecular weight fucoidan for P-selectin triggers its binding to activated human platelets. Biochim. Biophys. Acta, 1790 (2), 141-146.

101. Hiramatsu, Y., Tsujishita, H., and Kondo, H. (1996) Studies on selectin blocker. 3. Investigation of the carbohydrate ligand sialyl Lewis $\mathrm{X}$ recognition site of P-selectin. J. Med. Chem., 39 (23), 4547-4553.

102. Bouvard, C., Galy-Fauroux, I., Grelac, F., et al. (2015) Low-Molecular-Weight Fucoidan Induces Endothelial Cell Migration via the PI3K/AKT Pathway and Modulates the Transcription of Genes Involved in Angiogenesis. Mar. Drugs, 13 (12), 7446-7462.

103. Bouvard, C., Gafsou, B., Dizier, B., et al. (2010) alpha6-integrin subunit plays a major role in the proangiogenic properties of endothelial progenitor cells. Arterioscler. Thromb. Vasc. Biol., 30 (8), 1569-1575.

104. Qian, H., Tryggvason, K., Jacobsen, S.E., and Ekblom, M. (2006) Contribution of alpha6 integrins to hematopoietic stem and progenitor cell homing to bone marrow and collaboration with alpha4 integrins. Blood, 107 (9), 3503-3510.

105. Pomin, V.H. (2012) Fucanomics and galactanomics: current status in drug discovery, mechanisms of action and role of the well-defined structures. Biochim. Biophys. Acta, 1820 (12), 1971-1979.

106. Rouzet, F., Bachelet-Violette, L., Alsac, J.-M., et al. (2011) Radiolabeled fucoidan as a p-selectin targeting agent for in vivo imaging of platelet-rich thrombus and endothelial activation. J. Nucl. Med. Off. Publ. Soc. Nucl. Med., 52 (9), 1433-1440.

107. Sapharikas, E., Lokajczyk, A., Fischer, A.-M., and Boisson-Vidal, C. (2015) Fucoidan Stimulates Monocyte Migration via ERK/p38 Signaling Pathways and MMP9 Secretion. Mar. Drugs, 13 (7), 4156-4170.

108. Pineda, J.R.E.T., Kim, E.S.H., and Osinbowale, O.O. (2015) Impact of pharmacologic interventions on peripheral artery disease. Prog. Cardiovasc. Dis., 57 (5), 510-520.

109. Myers, S.P., O'Connor, J., Fitton, J.H., et al. (2010) A combined phase I and II open label study on the effects of a seaweed extract nutrient complex on osteoarthritis. Biol. Targets Ther., 4, 33-44. 
Catherine Boisson-Vidal obtained her PhD degrees from the Paris Nord University (France), where she studied the isolation, structural elucidation and structure-activity relationships of biologically active marine fucoidans under the guidance of Prof. Jozefonvicz and P. Durand (IFREMER). She undertook postdoctoral research in biomaterials at McMaster University (Hamilton, Canada) with $\mathrm{Dr}$ J. Brash. She took a lectureship at Paris Nord (1986-2003) and Paris Descartes University, where she is currently a CNRS research director and deputy director of Inserm research unit 1140.

Over the period 1989-2000, her main research focus was the development methods to prepare reproducible antithrombotic fractions of low-molecular-weight fucoidan and their structure-function relationship. She is currently developing new therapeutic approaches based on stem cell therapy, notably by attempting to enhance the proangiogenic potential of adult stem cells through their incorporation into sites of neovascularization, in both physiological and pathophysiological conditions. Her main focus is on the proangiogenic activity of fucoidan and its uses in vascular biotherapy and tissue regeneration. 